\title{
Expert System for Diagnosing Types of Diseases in Human Intestine Organs Using the Certainty Factor Method
}

\author{
Sistem Pakar Untuk Mendiagnosa Jenis Penyakit Pada Organ Usus \\ Manusia Menggunakan Metode Certainty Factor
}

\section{Elis Nurhayatmi}

Informatics Dept. Faculty of Information Technology

Universitas Serang Raya

Banten, INDONESIA

\section{Zaenal Muttaqin}

Information System Dept.

Faculty of Information Technology

Universitas Serang Raya

Banten, INDONESIA

\section{Ahmad Sugiyarta}

Jurusan Sistem Komputer, Fakultas Teknologi Informasi

Universitas Serang Raya

Banten, INDONESIA

\section{Ryan Naufal Hay's}

Information System Dept.

Faculty of Information Technology

Universitas Serang Raya

Banten, INDONESIA

Corresponding Autor: Zaenal Muttaqin
ELIS.NURHAYATMI@GMAIL.COM

D.ZAEY.VU@GMAIL.COM

SUGIYARTA@GMAIL.COM

RYAN.HAYS@GMAIL.COM

\begin{abstract}
Intestine is one of the organs of the digestive system in the human body which is shaped like pipes and act as gatekeeper food system for our bodies. Many people do not noticed his intestines health because they are too busy with his activity, or lazy to go to the doctor, even when hospital were many visitors there is also felt a lot of to waste time to queue up because they want to get their turn to be checked and a lot of costs to be incurred. This research discusses about creating expert system to diagnose intestinal diseases using certainty factor method. Applications developed with Visual Basic programming language with MySQL as its database. The results of this research able to do early diagnosis of the symptoms that is felt system users, and provide diagnostic results such as type of disease suffered, prevention and its information.
\end{abstract}

Keywords: Expert system, diagnosis disease, intestinal organs, certainty factor, visual basic

(C)2019 Nurhayatmi, Muttaqin, Sugiyarta, Hay's

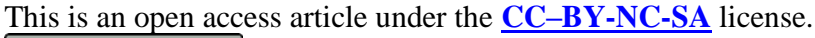




\begin{abstract}
ABSTRAKSI
Usus adalah salah satu organ sistem pencernaan pada tubuh manusia yang berbentuk seperti pipa-pipa dan berperan sebagai penjaga gawang sistem makanan bagi tubuh kita. Banyak orang yang tidak memperhatikan kesehatan ususnya karena terlalu sibuk dengan aktivitasnya sehingga malas untuk pergi ke dokter, bahkan pada saat rumah sakit sedang banyak pengunjung ada juga yang merasa banyak membuang waktu untuk mengantri karena ingin mendapat giliran untuk diperiksa dan banyak biaya yang harus dikeluarkan. Penelitian ini membahas tentang pembuatan system pakar sebagai alat bantu diagnosa penyakit usus menggunakan metode certainty factor. Aplikasi dikembangkan dengan bahasa pemrograman Visual basic dengan Mysql sebagai basis datanya. Hasil penelitian ini mampu melakukan diagnose awal terhadap gejalagejala yang dirasakan pengguna sistem, dan memberikan hasil diagnosa berupa jenis penyakit yang diderita, pencegahan dan informasinya.
\end{abstract}

Keywords: Sistem pakar, Diagnosa penyakit, organ usus, certainty factor, visual basic

\title{
1 Introduction
}

Perkembangan komputer saat ini telah mengalami banyak perubahan yang sangat pesat, seiring dengan kebutuhan manusia yang semakin banyak dan kompleks. Komputer yang pada awalnya hanya digunakan oleh para akademisi dan militer, kini telah digunakan secara luas di berbagai bidang, misalnya: bisnis, kesehatan, pendidikan, psikologi, permainan dan sebagainya. Hal ini mendorong para ahli untuk semakin mengembangkan komputer agar dapat membantu kerja manusia atau bahkan melebihi kemampuan kerja manusia, salah satunya adalah sistem pakar (Rohman, 2008). Menurut Kusrini (2008), sistem pakar adalah aplikasi berbasis komputer yang digunakan untuk menyelesaikan masalah sebagaimana yang dipikirkan oleh pakar. Pakar disini adalah orang yang memiliki keahlian khusus yang dapat menyelesaikan masalah yang tidak dapat diselesaikan oleh orang awam (Saputra, 2011)

Usus adalah salah satu organ sistem pencernaan pada tubuh manusia yang berbentuk seperti pipa-pipa dan berperan sebagai penjaga gawang sistem makanan bagi tubuh kita. Bila kita menyantap segala jenis makanan tanpa melakukan kontrol diri, maka usus akan sangat rentan terkena berbagai macam penyakit, seperti, penyakit infeksi usus besar, kanker usus besar atau kanker kolon berawal dari pertumbuhan sel - sel kanker dalam kolon yang disebut polip, penyakit sembelit atau konstipasi dan Radang usus besar atau yang biasa disebut dengan Colitis. Banyak orang yang tidak memperhatikan kesehatan karena terlalu sibuk dengan aktivitasnya sehingga malas untuk pergi ke dokter, bahkan pada saat rumah sakit sedang banyak pengunjung ada juga yang merasa banyak membuang waktu untuk mengantri karena ingin mendapat giliran untuk diperiksa dan banyak biaya yang harus dikeluarkan. Penderita penyakit usus sangat beresiko bila tidak cepat diobati oleh sebab itu yang harus dilakukan adalah mendeteksi penyakit usus pada manusia sedini mungkin salah satunya adalah dengan pemanfaatan teknologi informasi dengan membuat aplikasi yang dapat mendeteksi penyakit usus, yaitu sistem pakar.Saat ini sistem pakar banyak ditemui dan dibutuhkan dalam dunia kesehatan, industri maupun pendidikan, demikian juga di bidang pertanian. (Kaswidjanti, 2011)

Aplikasi sistem pakar yang dikembangkan dapat digunakan sebagai langkah awal untuk mengetahui tingkat kelainan pada usus sehingga pasien tidak perlu melakukan pemeriksaan lebih lanjut seperti pengecekan darah karena dengan adanya pemeriksaan lebih lanjut sangat membutuhkan banyak biaya dan tenaga. Dengan dibuatnya sistem ini dapat membantu pasien dalam melakukan pemeriksaan awal, agar mengetahui pasien menderita penyakit usus atau tidak. Pembuatan sistem pakar ini dikonsultasikan dengan seorang ahli dibidangnya yaitu dokter spesialis penyakit dalam, sementara teknik yang digunakan untuk pengambilan keputusannya digunakan metode inferensi Certainty Factor (CF)..

\section{Tinjauan Pustaka}

Rohman, dkk (2008) melakukan penelitian tentang rancang bangun aplikasi sistem pakar untuk menentukan jenis gangguan perkembangan pada anak. Penelitian tersebut membahas tentang sistem yang dapat menentukan jenis gangguan perkembangan pada anak dengan menggunakan metode certainty facktor (CF) diharapkan aplikasi sistem pakar yang dibuat ini mampu menganalisis jenis gangguan perkembangan yang dialami pasien berdasarkan gejala-gejala yang dimasukan oleh user.

Yudatama (2008) melakukan penelitian tentang sistem pakar untuk diagnosa kerusakan mesin mobil panther berbasis mobile. Penelitian tersebut membahas tentang sistem pakar untuk diagnosa kerusakan mesin mobil panther yang penyampaian informasinya menggunakan perangkat mobile cara meminta 
request dari user. Request tersebut akan diproses dalam sistem kemudian hasilnya akan dikirim lagi ke user dengan ditampilkan pada layar perangkat mobile.

Hamdani (2010) melakukan penelitian tentang sistem pakar untuk diagnosa penyakit mata pada manusia. Penelitian tersebut membahas tentang sistem pakar yang membahas tentang sistem pakar untuk mendiagnosa penyakit mata pada manusia menggunakan metode forward chaining yang bertujuan untuk menelusuri gejala yang ditampilkan dalam bentuk pertanyaan-pertanyaan agar dapat mendiagnosa jenis penyakit dengan perangkat lunak berbasis dekstop management system.

Parno, dkk (2012) melakukan penelitian tentang aplikasi sistem pakar untuk mendeteksi status gizi dan psikologis anak. Penelitian tersebut bertujuan untuk membuat aplikasi untuk membantu mendiagnosa status gizi anak, penjelasan akan kebutuhan gizi anak dan jenis psikologis anak yang perlu penanganan khusus, dengan adanya aplikasi tersebut diharapkan dapat memberikan informasi secara efisien mengenai status gizi dan psikologis anak yang sangat berpengaruh dalam tumbuh kembang serta kecerdasan otak, mengenal lebih jelas faktor yang mempengaruhi pemenuhan kebutuhan gizi balita, dan mampu mengurangi tingkat resiko dimasa mendatang.

Saputra (2011) melakukan penelitian tentang sistem pakar identifikasi penyakit paru-paru pada manusia menggunakan pemrograman Visual Basic 6.0. penelitian tersebut membahas tentang sistem pakar yang dapat mendiagnosa penyakit paru-paru pada manusia berdasarkan gejala-gejala yang pasien alami, selain itu sistem ini diharapkan dapat memasyarakatkan pengetahun atau ilmu para dokter/pakar/ahli penyakit paru-paru.

Kuwati (2011) melakukan penelitian tentang Sistem Pakar Pendeteksi Penyakit Saluran Pencernaan Pada Manusia Menggunakan Metode Forward Chaining dan Visual Basic 2010. Dalam sistem ini metode inferensi yang digunakan adalah forward chaining karena proses yang dialami dengan menampilkan gejala penyakit. Untuk membuat aplikasi ini dengan menggunakan bahasa pemrograman Visual Basic 2010. Dengan sistem pakar ini dapat mewakili seorang pakar medis agar mampu mendeteksi penyakit saluran pencernaan berdasarkan ciri-ciri dan gejala yang ada sehingga bagi masyarakat lebih menghemat waktu dan biaya.

Anggarwati, dkk (2009) melakukan Penelitian tentang sistem pakar diagnosis keracunan bahan kimia industri berbasis web. Sistem Pakar merupakan bagian dari ilmu komputer dan salah satu pengembangan dari kecerdasan buatan yang menggabungkan pengetahuan dan penelusuran data untuk memecahkan suatu masalah fisik juga tentang keracunan bahan kimia industri. Tujuan dari penelitian ini adalah membuat sistem pakar yang digunakan untuk diagnosis keracunan bahan kimia industri. Keracunan zat-zat kimia pada tubuh manusia dapat membahayakan kelangsungan hidup. Bahan kimia beracun tersebut merusak jaringan tubuh terpenting sehingga menganggu atau bahkan menghentikan fungsinya. Metode yang digunakan Forward Chaining.

Harihayati, dkk (2012) melakukan penelitian tentang sistem pakar mendiagnosa penyakit umum yang sering diderita balita berbasis web di dinas kesehatan kota Bandung. Penelitian ini dilakukan agar Sistem pakar ini dapat memberikan informasi mengenai jenis penyakit, gejala beserta pertolongan pertama. Pembangunan Sistem ini menggunakan metode inferensi forward chaining dan metode Depth First Transversal sebagai metode pencariannya. Sistem ini dibangun berbasis website agar dapat diakses oleh masyarakat luas dimana pun, sehingga dapat mengurangi resiko kesalahan yang dilakukan orang tua dalam melakukan pertolongan pertama kepada balitanya yang terindikasi penyakit dan keterlambatan dalam penanganan medis.

Rangkuti, dkk (2009) Penelitian tentang deteksi kerusakan notebook dengan menggunakan metode sistem pakar. sistem pakar ini digunakan untuk mendiagnosa berbagai macam jenis kerusakan yang terjadi pada notebook. Jenis kerusakan notebook yang dapat didiagnosa oleh sistem pakar ini adalah kerusakan LCD, Motherboard, Hardisk, Fdd, CD/DVD/CDRW/DVDRAM, Keyboard, Modem, Ethernet, Processor, bloothooth, mouse, baterai dan lain sebagainya. Salah satu kelebihan dari sistem pakar diagnosa kerusakan notebook tidak membatasi penggunaan sistem, selain itu proses pemeriksaan kerusakan notebook mempertimbangkan munculnya gejala khas paska setiap kerusakan, sehingga menyebabkan proses pendiagnosaan memakan waktu yang relatif singkat dan tepat. Dalam proses penarikan kesimpulan sistem menggunakan teknik Certainty factor (CF), dimana penentuan nilai CF dilakukan oleh pakar dari domain yang bersangkutan. Sistem dapat menghasilkan lebih dari satu diagnosa yang disusun berdasarkan bobotnya, sesuai dengan gejala-gejala masalah yang diinputkan oleh user. Sistem juga dilengkapi dengan ilustrasi gambar yang mempermudah pemahaman user pada saat proses konsultasi serta animasi prosedur pengambilan sparepart yang rusak untuk diperbaiki. Sistem ini berjalan dalam lingkungan internet, sehingga dapat diakses oleh banyak orang yang memiliki kepentingan terhadap penggunaan sistem ini. 
Ramadhan (2008) melakukan penelitian tentang sistem pakar dalam mengidentifikasi penyakit kanker pada anak sejak dini dan cara penangulangannya. Penelitian ini dilakukan untuk mempelajari aplikasi sistem pakar dengan metode forward chaining yang di implementasikan dalam aplikasi sistem pakar untuk menentukan penyakit kanker pada anak sejak dini sistem pakar ini dibuat dengan menggunakan bahasa pemrograman Visual Basic 6.0

Honggowibowo (2008) melakukan penelitian tentang sistem pakar diagnosa penyakit tanaman padi berbasis web dengan forward dan backward chaining. pada penelitian ini di rancang sistem pakar berbasis web menggunakan basis aturan (rule based reasoning) dengan metode inferensi forward chaining dan backward chaining yang dimaksud untuk membantu petani dalam mendiagnosa penyakit tanaman padi. sistem pakar diagnosa penyakit tanaman padi berbasis web yang telah dikembangkan mempunyai keunggulan dalam kemudahan akses dan kemudahan pemakaian. dengan fitur yang berbasis web yang dimiliki, sistem pakar untuk diagnosa penyakit tanaman padi yang telah dibangun dapat digunakan sebagai alat bantu untuk diagnosis penyakit tanaman padi dan dapat diakses oleh petani dimanapun juga untuk mengatasi persoalan keterbatasan jumlah pakar pertanian dalam membantu petani mendiagnosa penyaki tanaman padi.

Santoso, dkk (2008) melakukan penelitian tentang implementasi fuzzy expert system untuk analisa penyakit dalam pada manusia. Gejala merupakan suatu unsur penting dalam menentukan suatu pasien mengidap penyakit tertentu. Dalam kehidupan nyata, dokter akan menanyakan gejala-gejala pada pasiennya sebelum ia menentukan penyakit pasiennya. Dibuatnya software ini mengambil cara kerja dokter dalam menganalisa pasiennya. Cara kerja software menggunakan metode forward chaining dalam menentukan prediksi awal suatu penyakit setelah pasien memasukkan gejala yang dideritanya. Kemudian dari prediksi penyakit awal, software menggunakan metode backward chaining dalam menanyakan gejala-gejala lain yang pasien belum masukkan. Software ini dibuat dengan menggunakan metode Fuzzy Set dalam mengolah data pada knowledge-based system. Metode Fuzzy mengenal kebenaran secara parsial (keseluruhan). Hal ini sangat berguna agar sistem yang dibuat memiliki kecerdasan menyerupai manusia. Metode Fuzzy Set merupakan generalisasi dari crisp set (konvensional set) dimana elemen dalam suatu set mempunyai nilai interval 0 sampai dengan 1 . knowledge-based system dipakai untuk menyimpan informasi dari pakar tentang hubungan antara gejala dengan suatu penyakit menurut intensitas dan frekuensi.

Fitriastuti,dkk (2009) melakukan penelitian tentang aplikasi sistem pakar berbasis web untuk mendeteksi kerusakan perangkat keras komputer dengan metode backward chaining. perancangan aplikasi sistem pakar ini memanfaatkan metode backward chaining yang dipadukan dengan menggunakan PHP dan database MYSQL dan dirancang berbasis web karena aplikasi berbasis web akan lebih bersar manfaatnya. metode ini sesuai digunakan untuk memecahkan masalah diagnosa (schnupp,1989). Berdasarkan teknik dalam troubleshooting komputer, maka teknik backward adalah teknik untuk mendeteksi kesalahan pada komputer setelah dinyalakan sehingga mempermudah user dalam mendeteksi kerusakan pada komputernya. Handayani, dkk (2009) melakukan penelitian tentang Sistem Pakar untuk Diagnosis Penyakit THT Berbasis Web dengan "e2gLite Expert System Shell". Penelitian ini akan dikembangkan E2gLite Sistem Pakar E2gLite adalah sebuah shell sistem pakar yang dikembangkan oleh Expertise2Go yang berbasis internet dan dilengkapi applet Java. E2gLite memberikan kemudahan dalam hal pembangunan sistem pakar serta pelaksanaan konsultasi oleh pengguna. Sistem pakar yang dibuat dapat mendeteksi 23 jenis penyakit THT berdasarkan variasi input 38 gejala yang diberikan.

Harimurti, dkk (2012) melakukan penelitian tentang perancangan implementasi system pakar untuk memprediksi penyakit apendisitis dengan metode dampster-shafer. Aplikasi system pakar ini menghasilkan keluaran berupa kemungkinan penyakit apendisitis yang diderita berdasarkan gejala yang dirasakan oleh user. System ini juga menampilkan besarnya kepercayaan gejala tersebut terhadap kemungkinan penyakit apendisitis yang diderita oleh user. Biasanya nilai kepercayaan tersebut merupakan hasil perhitungan dengan menggunakan metode dempster-shafer.

\section{Penyakit Usus}

Usus merupakan salah satu organ sistem pencernaan pada manusia yang rentan terhadap berbagai macam penyakit, seperti:

1) Penyakit infeksi usus besar

Infeksi usus besar (shigellosis) merupakan penyakit diare yang disebabkan oleh infeksi bakteri shigella. shigellosis ditularkan dari orang ke orang melalui rute fekal-oral, melalui kontak langsung maupun tidak langsung dengan bahan tinja. hal ini umumnya terjadi jika tangan tidak dicuci dengan baik, terutama 
setelah menggunakan kakus atau menggantikan lampin (popok), dan melalui kontak seksual. infeksi shigella juga dapat diperoleh dari makan makanan yang tercemar dengan bakteri ini. lalat juga dapat membawa shigella dan dapat mencemari makanan.

2) Penyakit sembelit

Sembelit sebenarnya merupakan gejala penyerta dari suatu penyakit, terutama penyakit yang menyerang daerah perut. Gejala awal dari sembelit ditandai dengan buang air besar yang tidak normal. Disamping itu, lidah sering tertutup selaput putih tebal dan napas bau busuk. Penderita sering merasa pusing dan raut mukanya muram.

Penyebab sembelit antara lain bergesernya tali perut sehingga pergerakan isi perut tersumbat, usus besar mengalami kejang, proses pencernaan kurang sempurna dan kurang mengonsumsi makanan berkadar serat tinggi seperti sayur dan buah. Rasa ingin buang air besar yang sering ditahan juga dapat memicu terjadinya sembelit. Orang yang banyak duduk sering mengalami sembelit karena gerakan otot perutnya terganggu sehingga proses pencernaannya juga kurang sempurna.

3) Kanker usus besar

Kanker usus besar merupakan kanker yang menyerang daerah usus besar hingga dubur. Perkembangan kanker ini sangat lambat, sehingga sering diabaikan oleh penderita. Pada stadium dini, sering kali tidak ada keluhan dan tidak ada rasa sakit yang berat. Penderita kanker jenis ini umumnya datang kedokter setelah timbul rasa sakit yang berlebihan (stadium lanjut) sehingga pengobatannya menjadi lebih sulit.

4) Radang usus besar

Radang usus besar merupakan kondisi serius dan kronis yang dapat berakibat fatal pada kasus yang sangat parah. Radang usus besar adalah kondisi dimana satu atau beberapa bagian usus mengalami radang. Jika radang atau luka hanya terjadi pada lapisan permukaan usus besar, disebut colitis. Jika di dubur disebut proctitis. Dan jika terjadi pada usus besar dan dubur, maka disebut menderita colitis ulserative. Radang biasanya dimulai dari dubur dan menyebar ke usus besar tapi tidak meluas sampai usus halus. Akibat yang dirasakan adalah diare.

Radang menyebabkan sel-sel yang melapisi dinding usus mengelupas, terjadilah luka terbuka pada dinding usus (tukak) yang kemudian mengeluarkan lendir atau nanah. Pada kasus ini, diare sering disertai lendir, darah dan nanah.

\section{Certainty Factor}

Motode kepastian merupakan sebuah metode untuk menyatakan tingkat kepercayaan/kepastian terhadap sebuah kejadian (fakta/hipotesis) berdasarkan nilai yang diberikan oleh seorang pakar. Dalam metode kepastian ada beberapa cara untuk menentukan tingkat kepastian dalam sistem berbasis aturan. Salah satunya adalah dengan menggunakan nilai 1,0 atau $100 \%$ untuk sebuah kejadian pasti dan 0 untuk kejadian yang tidak mungkin. Konsep ini diusulkan untuk mengakomodasi ketidakpastian pemikiran seorang pakar yang sering menganalisa informasi dengan ungkapan seperti "mungkin", "kemungkinan besar", "hampir pasti" dan sebagainya. Notasi faktor kepastian digambarkan sebagai berikut :

$$
C F[h, e]=M B[h, e]-M D[h, e]
$$

Dimana, CF[h,e] menggambarkan faktor kepastian, $\mathrm{MB}[\mathrm{h}, \mathrm{e}]$ menggambarkan ukuran kepercayaan terhadap hipotesis $h$, jika diberikan evidence $e$ (antara 0 dan 1), MD[h,e] menggambarkan ukuran ketidakpercayaan terhadap hipotesis $h$, jika diberikan evidence $e$ (antara 0 dan 1). Ada tiga hal yang mungkin terjadi terhadap hipotesis yang muncul akibat evidence yang ada. Pertama, aturan dengan evidence e tunggal dan hipotesis $h$ tunggal, dimanan notasi faktor kepastian dapat dituliskan sebagai berikut:

$$
C F[h, e]=C F(e) x C F(\text { rule })
$$

Pada prakteknya, $\mathrm{CF}$ (rule) ditentukan oleh pakar, sedangkan $\mathrm{CF}(\mathrm{e})$ ditentukan oleh pengguna saat berkonsultasi dengan sistem. Kedua, aturan dengan evidence e ganda dan hipotesis $\mathrm{h}$ tunggal. Notasi faktor kepastiannya ditentukan oleh penghubung yang digunakan, apakah menggunakan disjungsi atau konjungsi. Untuk penghubung disjungsi dituliskan sebagai berikut :

$$
\text { IF } e 1 \text { AND } e 2 \ldots \text { AND } e_{n} \text { THEN h (CF rule) }
$$


sehingga perhitungan nilai CF ditentukan oleh notasi sebagai berikut :

$$
C F[h, e]=\min \left[C F(e 1), C F(e 2), \ldots, C F\left(e_{n}\right)\right] * C F(\text { rule })
$$

Sedangkan untuk penghubung konjungsi, dapat dituliskan sebagai berikut :

$$
\text { IF e1 OR e2 .. OR e } e_{n} \text { THENh (CF rule) }
$$

Sehingga perhitungan nilai $\mathrm{CF}$ ditentukan oleh notasi sebagai berikut :

$$
C F[h, e]=\max \left[C F(e 1), C F(e 2), \ldots, C F\left(e_{n}\right)\right] * C F(\text { rule })
$$

Ketiga, kombinasi dua buah rule dengan evidence berbeda (e1 dan e2) tetapi merujuk kepada hipotesis yang sama. Persamaan untuk menggabungkan dua buah $\mathrm{CF}$ adalah sebagai berikut :

$$
C F(C F 1, C F 2)= \begin{cases}C F_{1}+C F_{2}\left(1-C F_{1}\right) & \text { if } C F_{1}>0 \text { and } C F_{2}>0 \ldots(7 a) \\ \frac{C F_{1}+C F_{2}}{1-\left[\left|C F_{1}\right|,\left|C F_{2}\right|\right]} & \text { if } C F_{1}<0 \text { or } C F_{2}<0 \ldots \ldots(7 b) \\ C F_{1}+C F_{2}\left(1+C F_{1}\right) & \text { if } C F_{1}<0 \text { and } C F_{2}<0 \ldots .(7 c)\end{cases}
$$

Pada penelitian ini, formulasi perhitungan CF kombinasi menggunakan formula 7.a untuk perhitungan CF premis ganda, sedangkan untuk premis tunggal digunakan formula 4, dengan ketentuan CF yang dimasukan oleh pengguna berkisar antara (0 dan 1$)$.

\section{Metodologi Penelitian}

Penelitian ini dilakukan dengan tahapan berikut, pertama penentuan objek penelitian dilanjutkan dengan pengumpulan data baik berupa data Primer maupun data sekunder. Tahap selanjutnya adalah analisis data, pembuatan sistem, testing, dan Implementasi. Data yang dikumpulkan adalah data pasien dari RSUD Kota Cilegon yang mengalami penyakit usus.

\section{Hasil dan Pembahasan}

Berikut adalah hasil dari pengembangan sistem pakar diagnosis penyakit usus dengan certainty factor, Gambar 1 di bawah memperlihatkan urutan penggunakan aplikasi sistem pakar saat pasien akan berkonsultasi.

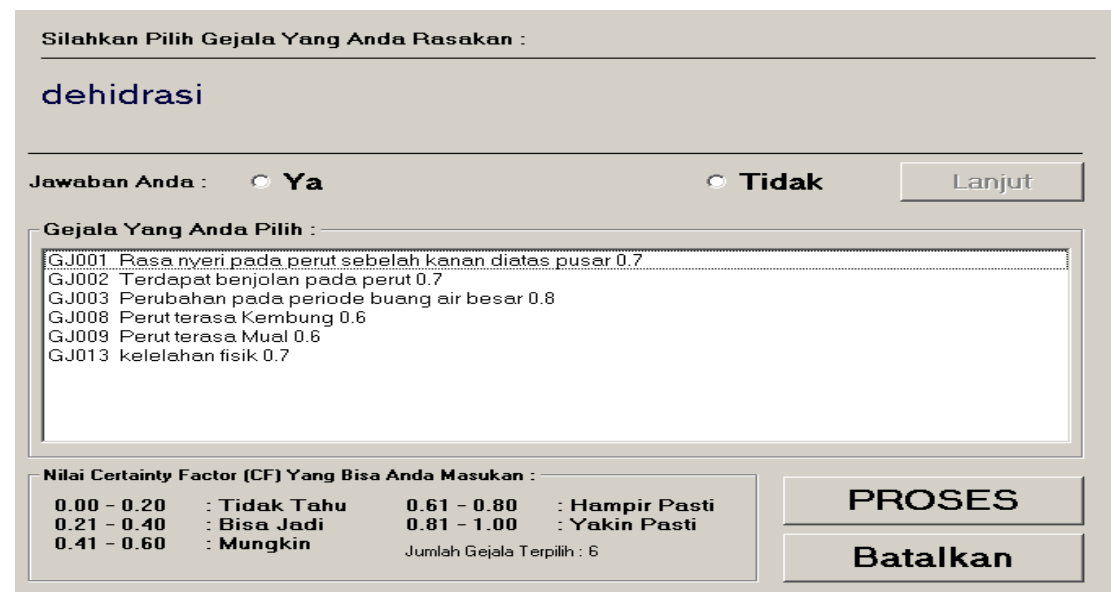

Gambar 1. Halaman Konsultasi Pasien 
Pada halaman konsultasi pemilihan gejala, pasien dapat melakukan konsultasi dengan cara menjawab pertanyaan yang diberikan oleh system dan memasukan nilai cf, pada halaman konsultasi terdapat tiga tombol yaitu tombol lanjut, proses dan batalkan. Halaman konfirmasi (lihat Gambar 2) gejala halaman ini menampilkan gejala-gejala yang sudah dipilih oleh pasien dan terdapat tombol telusuri penyakit (untuk mengetahui hasil diagnose dan prosentase tertinggi penyakit)

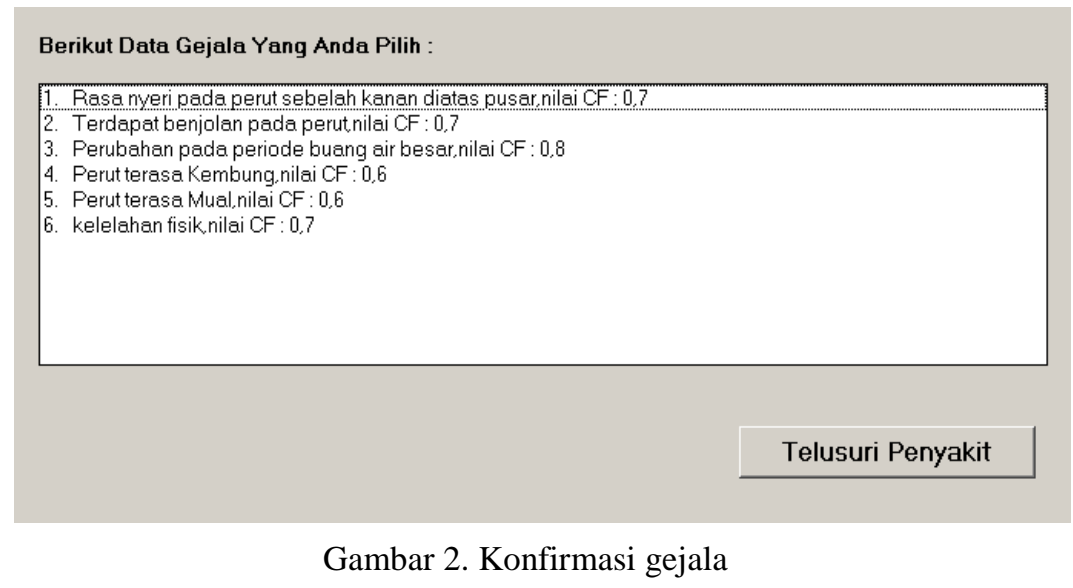

Gambar 3 memperlihatkan halaman hasil diagnose dapat di lihat prosentase tertinggi penyakit yang di derita oleh pasien Prosentase ini didapat dari perhitungan gejala-gejala yang di pilih oleh pasien.

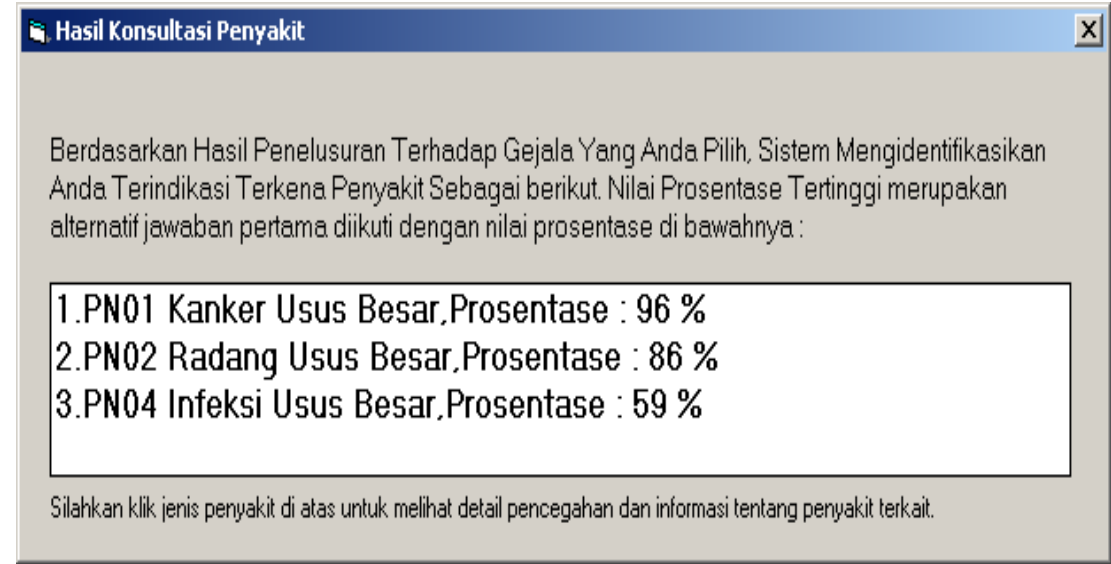

Gambar 3. Hasil diagnose penyakit

\section{Penutup}

Penelitian ini telah berhasil merancang sistem pakar untuk mendiagnosa jenis penyakit pada organ usus manusia menggunakan metode certainty factor, yang dapat memberikan kemudahan kepada pasien sebagai langkah awal mendeteksi penyakit pada organ usus manusia sedini mungkin. Namun demikian Aplikasi ini masih dapat dikembangkan agar lebih membantu kegiatan dokter dalam melakukan pemeriksaan terhadap pasien. Aplikasi ini hanya dapat mendiagnosis gejala-gejala awal penyakit pada organ usus manusia, untuk penelitian selanjutnya semoga dapat melakukan diagnosis pada tahap lebih lanjut, seperti memasukan hasil cek darah dari laboraturium.

\section{References}

Andayati, Dina., 2012, "Sistem Pakar Dalam Bidang Psikologi", Prosiding Seminar Nasional Aplikasi Sains \& Teknologi (SNAST) Periode IIIISSN: 1979-911X, Hal:B-286-B-293

Anggrawati, Lianita Tri., Riyadi, Ahmad., 2009, "Sistem Pakar Diagnosis Keracunan Bahan Kimia Industri Berbasis Web”, Jurnal Dinamika Informatika, Vol.3, No.2, Hal:129-138 
Fitriastuti, Fatsyahrina., Ekowati, Luluk Sri., 2009, "Aplikasi Sistem Pakar Berbasis Web Untuk Mendeteksi Kerusakan Perangkat Keras Komputer Dengan Metode Backward Chaining”, JANATEKNIKA, Vol.11, No.2, Hal: 95-106

Hamdani., 2010, "Sistem Pakar Untuk Diagnosa Penyakit Mata Pada Manusia”, Jurnal Informatika Mulawarman, Vol.5, No.2, Hal:13-21

Handayani, Lina., Sutikno, Tole., 2008, "Sistem Pakar Untuk Diagnosis Penyakit THT Berbasis Web Dengan E2glite Expert System Shell”, Jurnal Teknologi Industri Vol. XII,No.1, Hal: 19-26

Harihayati, Tati., Kurnia, Luthfi, 2012, "Sistem Pakar Mendiagnosa Penyakit Umum Yang Sering Diderita Balita Berbasis Web Di Dinas Kesehatan Kota Bandung”, Jurnal Komputer Dan Informatika (KOMPUTA), Edisi. I, Vol.1, Hal: 65-69

Harimurti, Nina., 2012, "Perancangan Implementasi System Pakar Untuk Mendeteksi Penyakit Apendisitis Dengan Metode Dempster-Shafer”, Jurnal Manajemen Informatika Vol. 1, No. 1, Hal:41-47

Honggowibowo, Anto Setiawan., 2009, "Sistem Pakar Diagnosa Penyakit Tanaman Padi Berbasis Web Dengan Forwarddan Backward Chaining", TELKOMNIKA, Vol.7, No.3, Hal:187-194

Kaswidjanti, Wilis., 2011, "Implementasi Mesin Inferensi Fuzzy (Studi Kasus Sistem Pakar Untuk Mendiagnosa Penyakit Tanaman Cabe Merah)", TELEMATIKA Vol. 7, No. 2, Hal:129-138

Kurniawan Rulianto., 2010. "PHP \& Mysql untuk orang awam", Maxikom.

Kuwati., 2011, "Sistem Pakar Pendeteksi Penyakit Saluran Pencernaan Padamanusia Menggunakan Metode Forward Chaining Dan Visual Basic 2010”, Jurnal Transit, Vol.1, No.1, Hal:1-10

Parno., Qoirina, Izhati., 2012, “Aplikasi Sistem Pakar Untuk Mendeteksi Status Gizi Dan Psikologis Anak”, Konferensi Nasional Sistem Informasi 2012, Hal:893-898

Ramadhan, Mukhlis., 2008, "Sistem Pakar Dalam Mengidentifikasi Penyakit Kanker Pada Anak Sejak Dini Dan Cara Penangulangannya", Jurnal SAINTIKON, Vol.10, No.2, Hal:125-135

Rangkuti, A. Haris., Andryana, Septi., 2009, "Deteksi Kerusakan Notebook Dengan Menggunakan Metode Sistem Pakar", Jurnal Artificial, ICT Research Center UNAS Artificial, Vol.3 No.1, Hal: 75-87

Rohman, Feri Fahrur., Fauziah, Ami., 2008, "Rancang Bangun Aplikasi Sistem Pakar Untuk Menentukan Jenis Gangguan Perkembangan Pada Anak”, Proceeding Seminar Media Informatika 2008, Hal:1-23

Santoso, Leo Willyanto., Intan, Rolly., Sugianto, Feky., 2008, "Implementasi Fuzzy Expert System Untuk Analisa Penyakit Dalam Pada Manusia", Seminar Nasional Aplikasi Teknologi Informasi 2008 (Snati 2008) Issn: 19075022, Hal:E-13-E-18

Saputra, Andi., 2011, "Sistem Pakar Identifikasi Penyakit Paru-Paru Pada Manusia Menggunakan Program Visual Basic 6.0", Jurnal Teknologi Dan Informatika(TEKNOMATIKA), Vol.1,No.3, Hal:202-222

Yudatama, Uky., 2008, "Sistem Pakar Untuk Diagnosis Kerusakan Mesin Mobil Panther Berbasis Mobile", Jurnal Teknologi, Vol.1, No.2, Hal:212-218 